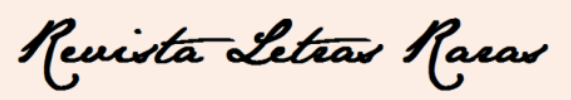

ISSN: 2317-2347 - Vol. 5, Ano 5, № 2 - 2016

\title{
O tempo nos romances de Antonio Tabucchi: análise do material e do discurso narrativo
}

Porque o tempo passa e devora as coisas, talvez permaneça somente a ideia.
Antonio Tabucchi, O gato de Cheshire

Marie-Line Cassagne ${ }^{2}$

O tempo é um dos temas magistrais na obra romanesca de Tabucchi, para quem o homem é submetido à sua marcha inexorável. Ele é ligado à visão de mundo do autor e se manifesta na ficção como uma preocupação que afeta aos personagens ${ }^{3}$. Alguns textos revelam uma concepção do tempo bastante pessoal. Em um espaço onde reina o jogo do inverso, a sobreposição de temporalidade reflete o gosto de Tabucchi pelo sonho, pela a invenção e a ilusão.

Vários são os personagens que se refugiam no passado para escapar das incertezas do presente. Eles recusam o que está por vir e vivem com a lembrança de uma felicidade fugitiva. Suas evocações do passado são impregnadas de nostalgia, de pesar ou de remorso.

Existem, entretanto, meios de resistir ao tempo que passa. A escrita biográfica é um deles, porque ela imortaliza o tempo através das palavras. "De uma vida, que pode ela restar de melhor senão o traço da escrita?” Pergunta o protagonista de Tristano Morre. A literatura como memória é outro meio, pois o escritor produz obras que sobreviverão ao tempo.

\section{O tempo revisitado}

\footnotetext{
* Tradução para o português do artigo Le temps dans les romans d'Antonio Tabucchi: Analyse de la matière et du discours narratif realizada por Glauber Rezende Jacob Willrich, mestrando em teoria literária pela Universidade Federal do Paraná (UFPR), e licenciado em Letras Francês pela Universidade Federal de Uberlândia (UFU). Email: glauber_rad@hotmail.com.

${ }^{1}$ Antonio Tabucchi, Il gioco Del roverscio, Milano, Feltrinelli, 2004 [1 $1^{\text {a }}$ edição: 1981]

${ }^{2}$ Doutora em Estudos Italianos pela Universidade Paris 4 Paris-Sorbonne.

${ }^{3} \mathrm{O}$ autor da carta intitulada Forbidden Games é um exemplo entre tantos: "E o que pensei no momento e o que me transcorreu através disso." (Antonio Tabucchi, Si sta facendo sempre più tardi, Milano, Feltrinelli, 2005 [1 ${ }^{\text {a }}$ edição: 2001], p. 41)
} 


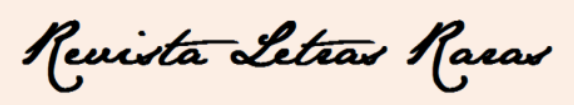

ISSN: 2317-2347 - Vol. 5, Ano 5, № 2 - 2016

No imaginário tabucchiano se aproximam personagens que vivem de acordo com uma concepção linear de tempo ${ }^{4}$ e outros que mantém uma relação problemática com o tempo. Desde 1975, data da publicação de seu primeiro romance, Tabucchi introduz um personagem no qual a cadeia temporal do antes e do depois é rompida. Volturno sofre, com efeito, do "mal do tempo", uma enfermidade que é declarada na adolescência e no qual os sintomas são os seguintes: "Respondera de improviso a uma pergunta que lhe haviam feito no dia anterior, recordava-se de fatos ainda não sucedidos, sofria duplamente a mesma desilusão"

Num crescendo, o personagem sofre em uma temporalidade interior que não corresponde à exterior. Ele conta os eventos seja falando do fim para retornar ao começo, seja misturando as histórias mais diversas. Ele se perde em um tempo que ele não pode administrar e sua inadaptação ao mundo faz dele o primeiro homo melancholicus dos personagens de Tabucchi.

Vinte anos mais tarde, o advogado Mello Siqueira de A cabeça perdida de

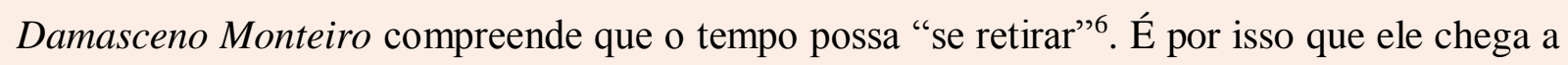
sonhar com sua avó criança:

[...] aquela mulher terrível que era meu pesadelo entrou em meus sonhos, e entrou também criança, que estranho, não teria imaginado que aquela velha megera fosse essa criança, e em vez disso, no meu sonho é uma criança [...] Sei que ela é minha avó, mas ao mesmo tempo é uma criança, como eu também sou $[\ldots]^{7}$

O sonho possibilita essa simultaneidade, ultrapassando a oposição linear entre passado e presente. Acrescentamos que o advogado espera por "cartas do passado" que lhes permitam compreender o que, na sua vida passada, havia lhe escapado, já que o jovem

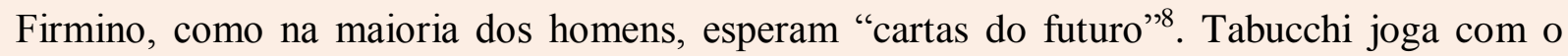

\footnotetext{
${ }^{4}$ É o caso, por exemplo, de Firmino, para quem, de acordo com o advogado Mello Siqueira "o tempo é um a fita que se desenrola diante, como um carro que corre sobre uma estrada desconhecida e cujo único interesse é o que se verá depois da próxima curva." (Antonio Tabucchi, La testa perduta di Damasceno Monteiro, Milano, Feltrinelli, 2004 [1 ${ }^{\text {a }}$ edição: 1997], p. 169)

${ }^{5}$ Antonio Tabucchi, Piazza d'Italia, Milano, Feltrinelli, 1998 [1 1ª edição: 1975], p. 25

${ }^{6}$ Antonio Tabucchi, La Testa Perduta di Damasceno Monteiro, cit. p. 169.

${ }^{7}$ Ibidem, p. 171.

${ }^{8}$ Ibidem, p. 128.
} 


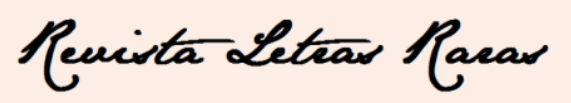

ISSN: 2317-2347 - Vol. 5, Ano 5, № 2 - 2016

tempo com a personagem Maria do Carmo em $O$ jogo do reverso, que gostava de desfrutar, na sua infância, do jogo de inversões. ${ }^{9}$

Em Se está fazendo sempre tão tarde, um romance que aparece em 2001, o autor da carta intitulada $O$ rio (il fiume) escreve "desde um tempo rompido" 10 , como se o tempo fosse um jogo mecânico reduzido em pedaços. Sua concepção de tempo não é outra senão essa do nosso mundo de referência, de nós leitores, pois para ele, presente, passado e futuro se confundem: “[...] a dimensão está invertida, só o que lembro tornou-se presente, e o que eu realmente sou ou deverei ser, o meu suposto agora, se tornou virtual e o vejo de longe como um telescópio virado."11

No conjunto, os narradores epistolares de Se está fazendo sempre tão tarde testemunham a dificuldade de Tabucchi por conservar o tempo como algo linear. É o que a fonte do ensaio Autobiografia póstuma nos mostra, onde o autor nos explica que:

Em verdade, não entendi ainda se somos nós que atravessamos o tempo ou se ele nos atravessa [...]. Entretanto, os personagens deste livro tem a ligeira sensação de estarem em atraso, ou mesmo em si mesmos. Ou às vezes tem a sensação de estarem antecipados ou de estarem atrasados, no sentido que havíamos intuído o que estava se sucedendo com eles. ${ }^{12}$

A ruptura do tempo, típica da pós-modernidade, se traduz por uma incapacidade dos personagens de se inscreverem no presente. Sempre no mesmo romance, o cigano cego da carta inclusa em Forbidden Games remonta ao longo do tempo e fala de um "horóscopo expirado", no qual seu interlocutor deverá ler ao contrário, até sua época onde ele jogara no pátio de uma casa pobre. ${ }^{13}$

Contenhamos com o fato de que, com Tabucchi, o tempo pode ser reversível e que é concebível predizer o passado. É o que revindica o cipreste a partir dos quais Tristano vem a procurar uma resposta ao enigma do tempo: "e assim, você me carrega, eu que prevejo o futuro, que prevejo o que tendo já sido, não poderá mais ser mudado..."14. A previsão não

\footnotetext{
${ }^{9}$ Antonio Tabucchi, Il gioco Del rovescio in $I l$ gioco Del rovescio, cit. p. 13

${ }^{10}$ Antonio Tabucchi, Si sta facendo sempre più tardi, cit. p. 35.

${ }^{11}$ Ibidem, p. 36.

${ }^{12}$ Antonio Tabucchi, Autobriografie altrui, Milano, Feltrinelli, 2003, p. 87.

${ }^{13}$ Antonio Tabucchi, Si sta facendo sempre più tardi, cit., p. 48.

${ }^{14}$ Antonio Tabucci, Tristano Muore, Milano, Feltrinelli, 2006 [1 ${ }^{\mathrm{a}}$ edição: 2004], p. 154. Essa possibilidade de reversão do tempo é um tema que encontramos também na novela "Carta de Casablanca" do Jogo do reverso,
} 


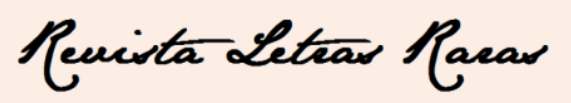

ISSN: 2317-2347 - Vol. 5, Ano 5, № 2 - 2016

concerne ao futuro, mas sim ao que ficou no passado e no qual Tristano não compreendeu nem como nem o porquê. Publicado em 2004, Tristano Morre nos faz retornar à complexidade da relação homem-tempo no qual havíamos comentado sobre Praça da Itália. No decorrer de um diálogo com o doutor Ziegler, o herói reconhece que ele para de viver em uma espécie de atemporalidade onde o tempo é como que suspenso e imóvel: “[...] tenho momentos em que sinto em mim que está mais tarde... tudo fica parado... e me sinto fechado no meio do tempo parado, como se tivesse estado momentaneamente transportado para outro mundo."15

Tabucchi é um escritor que não hesita em rejeitar, pela imaginação, as fronteiras do mundo sensível. Seus personagens evoluem em um mundo aos contornos incertos onde o fantástico se insinua no cotidiano. O diálogo com os mortos revela essa intrusão do insólito no mundo real. É também um dos aspectos da "revisitação" do tempo desaparecido que, segundo Carlos Gumpert, é uma constante temática do córpus tabucchiano. ${ }^{16}$ De fato, o romancista se pergunta, tal qual o herói de $O$ fio do horizonte, se "a distância que separa os vivos dos mortos é realmente tão grande?" ${ }^{17}$. O tema lhe é caro, pois, como ele o diz no Ateliê do escritor: "Evidentemente, existe em cada um de nós o desejo de dialogar com os que se foram, de interrogar os habitantes do outro lado para saber o que significara para eles viver, e em seguida deixar de viver". ${ }^{18}$

Desde os primeiros capítulos do Primeiro tempo de Praça da Italia, assistimos a uma cena que se caracteriza pela interpenetração da vida e da morte: Garibaldo filho e seu pai morto dialogam durante toda noite e é somente ao amanhecer que o pai reintegra a morte com resignação. A mesma situação se apresenta no capítulo quatro de Requiem, onde o protagonista narrador encontra seu pai, mesmo que este esteja morto já há muito tempo ${ }^{19}$. De maneira mais generalizada, os personagens do presente e os fantasmas do passado se cruzam

onde, como bem aponta Denis Ferraris ("As verdades da memória e da escritura na obra de Antonio Tabucchi" in Italies $\mathrm{n}^{\circ} 11$, Université de Provence, 2007, p. 110), o narrador pergunta a Lina de lhe conceber seus sonhos como se eles tivessem vozes, ou de sonhos de infância no qual podemos ainda tentar obter a satisfação ou a realização.

${ }^{15}$ Antonio Tabucchi, Tristano Muore, cit. p.116.

${ }^{16}$ Antonio Tabucchi, L'atelier de l'écrivain, Genouilleux, La passe du vent, 2001 [1a edição em espanhol : 1995], p. 156.

${ }^{17}$ Antonio Tabucchi, Il filo dell'orizzonte, Milano, Feltrinell, 1986, p. 10.

${ }^{18}$ Antonio Tabucchi, L'atelier de l'écrivain, cit. P. 197.

${ }^{19}$ A respeito do caráter autobiográfico deste episódio, recomendamos a leitura do ensaio Autobiografia Póstuma, cit., pp. 27-32. 


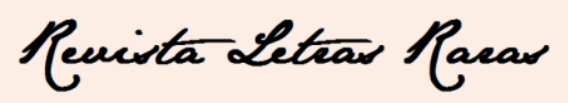

ISSN: 2317-2347 - Vol. 5, Ano 5, № 2 - 2016

ao longo de todo romance. A realidade e o sonho se confundem ${ }^{20}$, pois os vivos e os mortos dialogam entre eles. ${ }^{21}$ No capítulo três do mesmo romance, o narrador reencontra seu amigo Tadeus que morreu sem lhe ter confessado se havia ou não convencido Isabel a abortar. A ficção mistura o passado, o presente e o futuro. Anna Dolfi escreve a propósito de Requiem que "o tempo se sobrepõe. Requiem não fará a experiência até o delírio." "22. Lembremos-nos da passagem onde Tadeu evoca sua morte futura, que é pertencente ao passado para o protagonista: "tenho de morrer daqui a poucos anos com um enfarte e tu estás a passar-me raspanços?"23

O autor quer dar ao leitor o sentimento de pluralidade de tempo através dos personagens com uma contemporaneidade dissociada (Tadeus está, por sua vez, presente e ausente, pois está morto). No nível do discurso narrativo, os tempos verbais (presente, passado e futuro), se alternam em ambiguidade: "Olha, Tadeus, disse, a coisa mais misteriosa, a coisa que mais me intriga é o bilhete que tu me darás no dia da tua morte, lembras-te?"24

O episódio da reaparição do pai corrobora com a ideia de uma dimensão temporal onde tudo é possível. Durante doze horas (do meio dia à meia noite) que dura a alucinação do protagonista, o pai afirma que "estamos em 1932" 25 , enquanto que a ação se situa no fim do século XX, em uma data não precisa ${ }^{26}$.

Se está fazendo sempre tão tarde confirma a fascinação que as vozes do além exercem sobre Tabucchi. Os mortos retornam se inserindo na vida dos vivos, ele os obsecam e os interrogam. Se o autor da carta $O$ rio se contenta em escutar as vozes de seus defuntos

\footnotetext{
${ }^{20}$ Sobre a dialética entre real/imaginário em Réqueim, consultemos a obra de Nives Trentini, Una scrittura in partita doppia. Tabucchi fra romanzo e raconto, Roma, Bulzoni, 2003, pp. 171-190.

${ }^{21}$ Adequadamente, Stefano Lazzarin aproxima Requeim da tradição dos textos fantásticos. Sobre este ponto, ver seu artigo "Materiali su Tabucchi e il fantastico" in Chroniques Italienes, Université de la Sorbonne NouvelleParis III, Série Web, ${ }^{\circ}$ 2, 4/2002, pp. 11-13. Sobre o fantástico em Réquiem, podemos ler igualmente a obra de Flavia Brizio-Skov, Antonio Tabucchi, Navigazioni in um arcipelago narrativo, Cosenza, Pellegrini, 2002, pp. 103-105.

${ }^{22}$ Anna Dolfi, Tabucchi, la specularitá, il rimorso, Roma, Bulzoni, 2006, p. 23.

${ }^{23}$ Antonio Tabucchi, Requiem, Traduzione di Sergio Vecchio, Milaino, Feltrineli, 1997 [1992], p. 39.

${ }^{24}$ Ibid., p. 40. Quando, duas páginas depois, o protagonista retorna sobre as razões que conduzimos a vir sobre Tadeus,ele emprega novamente o futuro: "por causa daquele bilhete que me escreverá, antes de morrer." (1991, cit. p. 42).

${ }^{25}$ Ibid, p. 59

${ }^{26}$ No capítulo nove, o convidado se dirige ao protagonista incluindo-o nos "homens do fim do século". Uma confirmação dessa data nos é fornecida no capítulo seis, quando a esposa do guardião do phare, evocando o passado, faz alusão a 1971, ano em que ela se casou e se instalou na casa do phare.
}

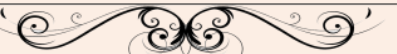




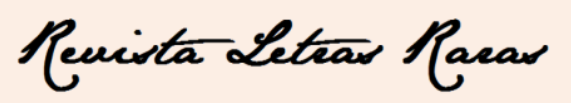

ISSN: 2317-2347 - Vol. 5, Ano 5, № 2 - 2016

carregados pelo $\operatorname{mar}^{27}$, o narrador de Da dificuldade de se libertar do arame farpado dialoga com seus entes queridos desaparecidos: "Era assim que eu pensava na minha morte, e falava com eles. As vozes eram claras, nítidas [...] Me contaram de suas vidas, que não era vida, e me disseram que era tranquila, porque da vida que haviam tido não tinham nada para realizar". 28

O "mal do tempo" do qual sofre Volturno em Praça da Italia se encontra na construção do romance que é somente uma narração linear de eventos sucessivos se desenrolando em um quadro temporal preciso. ${ }^{29}$ No nível do discurso narrativo, a lógica é revertida desde a primeira página do livro que começa com um epílogo retraçando a morte de Garibaldo filho aos sessenta anos. Para conhecer as circunstâncias dessa morte, os eventos que a precedem, o leitor deve abater a história que lhe é apresentada, o que distancia o romance das sagas familiares tradicionais. Entretanto, a narrativa é marcada pelos retornos para trás. No capítulo 48 do segundo tempo, Asmara conta a agonia de Melchiorre que mantinha a velha a noite. A narração retrospectiva é introduzida por um "conte-me" 30 de Garibaldo filho e passamos do dia à noite da velha antes de chegar ao momento da ação. A continuidade cronológica é rompida não somente pelas analepses, mas também pelas prolepses. O primeiro tempo se abre com a morte de Garibaldo pai (capítulo 1), mas é somente no capítulo 30 que vemos a narração do roubo do celeiro de Bourgo, no qual ele morre. Quanto à morte de Anita, esta é brevemente evocada no fim do capítulo 26 do Primeiro tempo, mas ela só é descrita no capítulo 50 do Segundo tempo.

Em O Pequeno navio, outro romance da juventude de Tabucchi, observamos a mesma reversão de ordem tradicional do discurso narrativo. Por um lado, o título do primeiro capítulo da Primeira parte (“do fim ao início”) é significativo por um distanciamento em direção aos códigos ou regras, por outro lado, ele o sustenta uma analepse no capítulo "aviões de papel" da Segunda parte e uma prolepse no capítulo "nomes aritméticos e cabelos

\footnotetext{
${ }^{27}$ Antonio Tabucchi, Si sta facendo sempre più tardi, cit. p.34.

${ }^{28}$ Ibidem, p. 92.

${ }^{29}$ Sobre a influência da arte cinematográfica na construção de Praça da Italia, consultemos o artigo de Thea Rimini, "La cine(biblio)teca di Tabucchi: il montaggio di Piazza d'Italia" in Italies no 11, Ed. cit., pp. $321-348$. Sobre o mesmo tema ver também Flavia Brizio-Skpv, op. cit., p.34.

${ }^{30}$ Antonio Tabucchi, Piazza d'Italia, Ed. cit. p. 110.
} 


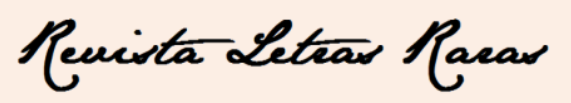

ISSN: 2317-2347 - Vol. 5, Ano 5, № 2 - 2016

vermelhos" da Primeira parte ${ }^{31}$. A estes se acrescentam também bruscos saltos temporais que rompem com a continuidade da narração. ${ }^{32}$

Enfim, Afirma pereira, um romance da fase madura do autor ${ }^{33}$, é um primeiro exemplo de deslocação temporal. O verbo do leitmotiv "afirma" está no presente quando a narração é no passado. O vai-e-vem contínuo entre os dois tempos coloca em causa a linearidade temporal e contribui com a organização da obra.

\section{A lembrança do passado}

A lembrança ocupa um lugar importante nos romances de Tabucchi, no qual vários de seus personagens revivem seu passado pela memória. Eles se colocam mentalmente em uma situação anterior e provam sentimentos já vividos ou que eles creem ter vividos. A errância em Lisboa do protagonista narrador de Requiem o conduz a retornar sobre certas etapas fundamentais de sua existência e a viver suas lembranças na atualidade da jornada particular que se situa. Em Afirma Pereira, o herói está bastante ligado à memória de sua mulher, e ele evolui entre suas lembranças do passado e o mundo que o cerca desde que ela morreu. Para os narradores de Se está fazendo sempre tão tarde, o passado continua a ser presente neles, em um impossível trabalho de luto. O sonho abole a distância temporal. É o caso do autor de Boa notícia de casa no qual a esposa morta é uma presença em todos os instantes, ${ }^{34}$ e igualmente o autor de Da dificuldade de se libertar do arame farpado para quem a lembrança cria a ilusão de alucinação de tempo: "E as tempestades de verão de trinta anos antes de retornar como que por encanto, eu o vi de novo, porque as coisas também podem reviver ainda mais um pequeno

\footnotetext{
${ }^{31}$ No primeiro caso, a narração (os achados de Capitano Sesto e seu amigo Socrates) é intercalada pela narração retrospectiva, da parte de Socrates, sobre a morte de Ivana Rosa. No segundo caso, o capítulo se fecha com uma alusão à partida de Sesto, mas é somente dois capítulos mais tarde, no fim do capítulo "Água" que ele entra em diegese.

${ }^{32}$ No capítulo "a lei da gravidade" da Primeira parte, o salto temporal é de quatro ou cinco anos: "Para contar o resto Capitano Sesto foi então forçado a fazer um salto para frente de quatro ou cinco anos, quando os dois gêmeos estavam tacitamente preparando a encenação de suas indubitáveis belezas." (Antonio Tabucchi, $O$ Pequeno navio, Milano, Mondadori, 1978, p. 29).

${ }^{33}$ Este foi publicado pela primeira vez em 1994 quando Tabucchi tinha cinquenta e um anos.

${ }^{34}$ Antonio Tabucchi, Si sta facendo sempre più tardi, cit. p. 106: “Agora os anos são passados, tantos, minha cara, muitíssimos. E mesmo ainda te lembramos, te recordo. Você está sempre comigo, você sabe, me acompanhando em cada momento de minha vida."
}

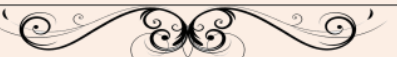




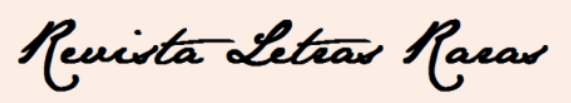

ISSN: 2317-2347 - Vol. 5, Ano 5, № 2 - 2016

instante fugitivo como gotas de chuviscos que tamborilam sobre o vidro e dilata o universo da visão". 35

Para o narrador de Vésperas de Ascensão, a evocação do passado permite emancipar alguns momentos de felicidade da ordem do tempo. O tempo perdido da felicidade amorosa pode ser encontrado e a lembrança recriada tem o poder de parar o tempo: "Por mim, conclui ele, é como se estivesse parado o tempo, tu sabes?". ${ }^{36}$

O fenômeno da memória involuntária é marginal em Tabucchi. ${ }^{37}$ Em geral, o personagem lembra voluntariamente de uma ação ou memória passadas. Basta pensar no jovem Corrado Zanardelli que se relembra, com os mínimos detalhes, de seu diálogo com uma das filhas de Argia, ${ }^{38}$ ou de Roux que se lembra da visita a uma capela com seus amigos. ${ }^{39} \mathrm{Na}$ mesma perspectiva, se inscreve a recorrência do verbo "recordar" que, por exemplo, é empregado em dez reprises da carta Meus olhos claros, meu cabelo cor de mel. ${ }^{40}$

As lembranças nascem por de trás do vidro de um trem ou de um carro. O trem é propício ao devaneio e deixa o viajante livre para caminhar nas errâncias de seus pensamentos. Deixando rolar sobre seus olhos as praias que distanciam a linha Lisboa-Parede, Pereira se lembra das matinês na praia quando ele era estudante em Coimbra:

Me vieram a mente os tempos de Coimbra, quando andava nas praias próximas do porto. O mar era geladíssimo, naquelas praias do norte, mas era possível nadar pela manhã inteira [...]. Nós admirávamos e o mestre dava as boas vindas dizendo: eis aqui os estudantes de Coimbra. ${ }^{41}$

Em O pequeno navio, é uma viagem de carro que provoca o mecanismo do sonho. No último capítulo do romance, quando Capitano Sesto se junta à cidade de pedra de seus ancestrais, as paisagens atravessadas favorecem o retorno de seu passado. ${ }^{42}$

\footnotetext{
${ }^{35}$ Ibidem, p. 93.

${ }^{36}$ Ibidem, p. 179.

${ }^{37}$ Um exemplo de memória involuntária se encontra no capítulo 6 de Requiem. Desde quando ele entrou na mansão do phare, onde ele viveu há um ano, o protagonista reconhece o odor da casa, motivo suficiente para fazer ressurgir o passado:’Entramos, e eu de subito reconheci o cheiro da casa [...] e me veio à memória..." (cit., p. 90)

${ }^{38}$ Antonio Tabucchi, O Pequeno Navio, cit., p. 55.

${ }^{39}$ Antonio Tabucchi, Notturno Indiano, Palermo, Sellerio, 2004 [1 $1^{\mathrm{a}}$ edição: 1984]

${ }^{40}$ Antonio Tabucchi, Si sta facendo sempre più tardi, cit., pp. 183-193.

${ }^{41}$ Antonio Tabucchi, Sostiene Pereira, Milano, Feltrinelli, 2006 [1 $1^{\text {a }}$ edição: 1994], p. 105.

42 Antonio Tabucchi, O Pequeno Navio, cit., p. 185.
} 


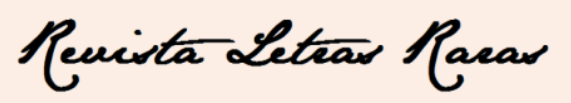

ISSN: 2317-2347 - Vol. 5, Ano 5, № 2 - 2016

Com Tabucchi, a música está intimamente ligada à memória e ao ressurgimento do passado $^{43}$. Ela permite fazer emergir das suas profundezas as lembranças do tempo que se foi. No capítulo 6 de Requeim, o protagonista narrador visita a casa do phare, se senta ao piano e toca um trecho de Chopin. É aí que ele revive no espírito as noites em que ele escutava em seu quarto os noturnos do pianista polonês. ${ }^{44}$ Em Afirma Pereira, a música é, por sua vez, um gatilho da lembrança e um vetor da nostalgia. Vemos quando Pereira, sentado em um banco, escuta dois pequenos velhos tocando viola e guitarra:

\begin{abstract}
Eram dois velhos que tocavam, um no violão e outro na guitarra, e tocavam comoventes músicas de Coimbra de sua juventude, de quando eram estudantes universitários [...] E ainda ele, naquele tempo, tocava a viola nas festas estudantis, era magro e ágil, e era apaixonado pelas garotas. ${ }^{45}$
\end{abstract}

A fotografia pode ser também um gatilho para as lembranças ${ }^{46}$. De maneira mais geral, ela representa o contato com o passado, e até mesmo com o além ${ }^{47}$. Encontramos várias fotos de pessoas desaparecidas nos romances de Tabucchi: a de Carlo Nobodi, criança em $O$ Fio do Horizonte, e a da Marilyn-Rosamunda no vestiário da casa de Tristano. A fotografia é testemunha de um evento, feliz ou infeliz. Ela nos traz de volta a um momento que não existe mais, mas que perdura na medida em que ela imortaliza a pessoa fotografada ${ }^{48}$. No caso de Pereira, a foto de sua esposa defunta data de 1927, quando o casal fazia uma viagem a Madrid. A atitude que ele tomou de falar com ela transforma a falta em presença, encerrando o jornalismo no passado.

O tempo se enriquece graças à conservação e ao acumulo das lembranças. Embora os personagens tenham sempre dois tempos como fio condutor das lembranças do passado, os romances O Pequeno navio (1978) e Tristano Morre (2004) diferem quanto à maneira de

\footnotetext{
${ }^{43}$ Isso se verifica não só nos romances mas também nas novelas do escritor. Para análise deste tema nas narrativas, consultar o artigo de Raymond Abbrugiati, "La musique du malentendu" in Italies $\mathrm{n}^{\circ} 11$, cit., pp.5458.

${ }^{44}$ AntonioTabucchi, Requiem, Ed. cit., p. 90

45 Antonio Tabucchi, Sostiene Pereira, cit., p. 20.

${ }^{46}$ É o caso do autor da carta Para que serve uma harpa de uma corda só? que se lembra do passado porque viu em um jornal a foto de uma mulher que amou. (Antonio Tabucchi, Si sta facendo sempre più tardi, Ed. cit., pp. 107-121)

${ }^{47}$ Contemplamos aqui na foto de Tadeus que orna sua tumba no cemitério de Lisboa e que serve à reaparição do personagem (Antonio Tabucchi, Requiem, cit., p. 34 e p. 37)

${ }^{48}$ Nives Trentini consagrou páginas interessantes sobre a revivescência do passado pela fotografia, apoiando seu estudo sobre Si sta facendo sempre più tardi (op. cit., pp. 101-121)
} 


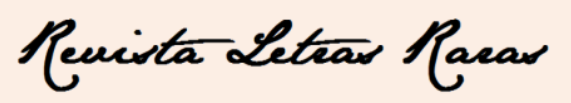

ISSN: 2317-2347 - Vol. 5, Ano 5, № 2 - 2016

reconstruir esse passado. Essa diferença reflete a evolução que marca a escrita de Tabucchi, desde as obras jovens até aquelas da maturidade. No primeiro romance, Capitano Sesto reconstitui, aos trinta anos, a história de sua família falando de um retrato encontrado no sótão da casa de seus pais. Ele acaba de comprar um caderno em uma loja de sua cidade natal, e decide retranscrever os eventos mais marcantes de sua existência. Com ele, a memória não vem das sensações ou de atmosferas, mas de lembranças precisas que ele integra nos "arquivos de lembranças memoráveis" ou nas "fichas de lembranças memoráveis" "49. Apesar dos anos passados, as lembranças são vivas e sua empreitada se quer rigorosa. ${ }^{50}$

Por outro lado, no segundo romance, Tristano reúne os fragmentos de sua história pessoal de uma maneira desorganizada. Ele recusa a ordem cronológica dos eventos e insere rupturas e retornos para trás na sua reconstrução do passado ${ }^{51}$. Suas lembranças, como seus pensamentos, são às vezes confundidos e não é raro que ele salte de um assunto para outro. Ele convence a si próprio que seu relato pode parecer "sem construção" e que ele é "como uma partitura musical onde chega, de tempos em tempos, um instrumento e fala à sua vez, com sua voz." ${ }^{2}$ Não há nenhuma dúvida que Tristano morre, com seu fluxo narrativo aparentemente caótico, não caia no pós-moderno. Os motivos retornam em variações, os personagens se misturam e ensaiam múltiplas combinações. Rosamunda e Daphné aparecem com outros nomes, Marilyn, Mary, Guagliona para a primeira. Mavri Elià para a segunda. Elas se sobrepõem às vezes na narração dos fatos. ${ }^{53}$ As lembranças passam sobre o crivo de uma consciência que se derrama sobre o efeito combinado da gangrena, da morfina, da nostalgia e da ironia. A evocação do passado é interrompida por instantes do presente da diegese, por comentários sobre a enfermidade sobre a qual ele vai dizer, ou por observações diversas. Os tempos verbais do discurso narrativo oscilam constantemente entre presente e pretérito imperfeito. A passagem onde o herói se recorda do ritual do poema dominical lido

\footnotetext{
${ }^{49}$ As expressões "archivio del ricordi ricordabili" e "shedario dei dicordi ricordabili" aparecem em cinco reprises do romance: a primeira nas páginas 108, 109, 125, 133 e 134 da edição citada, a segunda nas páginas 112, 119, 121,124 e 137.

${ }^{50}$ Entretanto, ela não exclui necessariamente o recurso à imaginação quando Capitano Sesto reconstitui a história de seus ancestrais. Desde a primeira página de $O$ Pequeno navio, Tabucchi escreve que "começando, portanto, a contar aquela distante fuga, Capitano Sesto reconstrói a cena com sua imaginação” (Ed., cit., p. 11)

${ }^{51}$ Um exemplo nos é fornecido pelo relato da morte do soldado alemão que Tristano matou na cidade grega de Plaka. Na edição citada do romance, a narração se interrompe na página 15, para ser somente retomada na página 22. Entre-tempos, o protagonista volta à realidade presente (o mês de agosto de 1999) e evoca outra lembrança, qual seja, a do cão Vanda.

${ }^{52}$ Antonio Tabucchi, Tristano muore, cit., p. 51.

${ }^{53}$ Ibidem, p. 50: "Devo me corrigir, qual espécie de sonho que estava te contando, o da praia, não era Rosamunda, era Daphne... Ora, o que acho melhor, em qual cabana de galhos Tristano entrou com sua Daphne".
} 


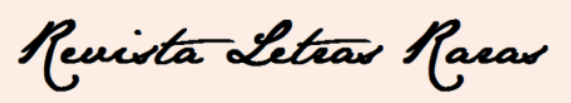

ISSN: 2317-2347 - Vol. 5, Ano 5, № 2 - 2016

por Frau é um exemplo: "O cerimonial era feito assim, eu sentado na poltrona, na sala de estar, quinze minutos antes de iniciar a lição, porque os garotos deveriam esperar, dois minutinhos, o avô não compromete os horários, mas no resto comprometia tudo ${ }^{54}[\ldots]$ ”

Tristano se aflige ao se reencontrar nas lembranças e perde, em alguns momentos, o fio condutor de seu relato. Ele admite que "as lembranças parecem ser às vezes gelatina" 55 e que ele não está totalmente certo de ter verdadeiramente vivido tal ou tal episódio - talvez ele o tenha inventado ou sonhado? O "eu" narrativo introduz a dúvida sobre o valor de suas próprias lembranças quando sua memória o trai: "Era um dia de verão e Tristano se recorda azuladamente, e também a cidade recorda azul, mesmo se, na realidade, era uma cidade rosada, com as casas rosas e amarelas ao longo das valas cercadas de muros antigos que chegavam ao mar." 56

As lembranças podem se confundir com o sonho e a fronteira que separa o real do imaginário se torna tênue. Como escreve Tabucchi na novela As trutas que se lançam entre as pedras me recordam de sua vida, "quando eles estão longe, as lembranças se parecem com a imaginação, elas são como um sonho" "57. Isso é verídico em Tristano Morre, onde o herói lança a confusão no espírito do leitor jogando com as palavras: "a lembrança de um sonho... ou talvez o sonho de uma lembrança... ou talvez os dois." 58

A nostalgia e o remorso associados à memória permeiam os diferentes romances ${ }^{59}$. A sombra do passado paira sobre o presente dos narradores de Se está fazendo sempre tão tarde, que são nostálgicos de uma relação amorosa acabada (seguida da separação de dois amantes ou da morte da mulher amada). A melancolia colore suas lembranças e o que se foi (e

\footnotetext{
54 Ibidem, p. 26.

55 Ibidem, p. 37.

${ }^{56}$ Ibidem, p. 57. Já no Pequeno navio, Tabucchi tinha consciência que a memória pode ser enganadora. (cit., p. 175: "é curioso como a memória procura deformar a ralidade.") Este tema reaparece em Noturno Indiano onde a memória é "uma formidável falsaria" (cit., p. 80).

${ }^{57}$ Antonio Tabucchi, L'angelo Nero, Milano, Feltrineli, 2005 [1ª edição: 1991], p. 98. No Ateliê do escritor, Tabucchi se explica sobre a dialética da memória e do imaginário: "creio que as lembranças podem ser alteradas por nossa maneira de viver, por nossa maneira de ver, por nosso modo de pensar, e, sobretudo, por nossa maneira de sentir as coisas. Por todas essas razões, creio que a lembrança e a imaginação andam juntas." (cit., p. 138).

58 Antonio Tabucchi, Tristano muore, Ed. cit., p. 122: “...devo ter sonhado, sonhei com Tristano... ou foi a recordação de um sonho... ou talvez o sonho de uma recordação... ou foi ambos os dois... Ah, escritor, que confusão..."

${ }^{59}$ Especifiquemos que, ao contrário dos outros heróis, raros são os personagens de Tabucchi que tem a nostalgia de sua infância, sem dúvida porque suas criações não comprovaram jamais um tal sentimento. No Ateliê do escritor, ele reconehce que "eu não tenho nostalgia da infância [...] me sinto melhor no mundo adulto." (cit., p. 54)
} 


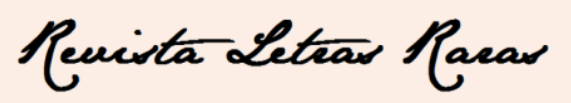

ISSN: 2317-2347 - Vol. 5, Ano 5, № 2 - 2016

que não será mais) as mantêm em um estado em que viver equivale quase sempre a se lamentar ${ }^{60}$. Em Afirma Pereira, o protagonista cultiva a nostalgia dos anos em que sua mulher não tinha ainda deixado de existir. Se persuadindo que os únicos momentos de felicidade aparecem no passado, ele recusa a possibilidade de uma felicidade atual. Requiem nos oferece outro exemplo de nostalgia do passado, quando Tadeus, no capítulo 3, lamenta a época em que ele e o narrador andavam de braços dados nas ruas de Lisboa. ${ }^{61} \mathrm{Em}$ A cabeça perdida de Damasceno Monteiro, o advogado Mello Siqueira não pode se impedir de ser nostálgico quando se lembra da casa de sua infância. ${ }^{62}$ Constatamos, então, que todos estes personagens sofrem diante do caractere imutável do passado.

Os remorsos se dão à impossibilidade de mudar o que passou. Ele é onipresente em Requeim $^{63}$, onde, segundo o pintor copiador, ele se assemelha a uma doença viral, herpes zoster, que é sempre latente diante daqueles que são atingidos: “[...] acho que o herpes é um pouco como o remorso, fica adormecido dentro de nós e um belo dia acorda e ataca-nos, e depois volta a adormecer porque nós conseguimos amansá-lo, mas fica sempre dentro de nós, não há nada a fazer com o remorso. "64

O remorso atormenta o protagonista do romance que estima que deveria ter se comportado diferentemente diante do cirurgião que operou seu pai. ${ }^{65}$ Tristano o é também roído pelo remorso, de um lado por que ele abandonou Daphne, de outro, porque ele faltou com a educação de Ignácio, o filho adotivo de Marilyn-Rosamunda. Em Afirma Pereira, o remorso é ligado ao lamento e ao arrependimento. Quando o herói questiona sobre seu passado, ele sente a necessidade de se arrepender sem saber bem do que. ${ }^{66}$ Ele se sente culpado e não é por acaso se ele traduz para o jornal em que trabalha a novela Honorine de

\footnotetext{
${ }^{60}$ É o caso do autor da carta Vigília de ascensão que fala das imagens "de pesar e arrependimento" quando evoca o passado e a mulher amada que o abandonou. (Antonio Tabucchi, Si sta facendo sempre più tardi, Ed., cit., p. 178).

${ }^{61}$ Antonio Tabucchi, Requiem, cit., p. 40.

${ }^{62}$ Antonio Tabucchi, La testa perduta di Damasceno Monteiro, cit., p. 123: "respiro com nostalgia".

${ }^{63} \mathrm{O}$ remorso é um tema recorrente na obra tabucchiana. Sobre este ponto, a coleção Anjo Negro é próxima de Requiem como oportunamente observou Anna Dolfi (op.cit., pp. 227-242).

${ }^{64}$ Antonio Tabucchi, Requiem, cit., p. 79.

${ }^{65}$ Ibid, p. 62.: "Sinta padre, disse, não sei se fiz bem, mas talvez eu tivesse melhor me comportado de outro modo, se o tivesse esbofeteado, que tipo seria uma solução mais corajosa, mas não o fiz, e é por isso que tenho esse sentimento de culpa."

${ }^{66} \mathrm{O}$ drama de Pereira é este no qual um homem lutando com sua consciência e com seu passado. No capítulo 16 do romance, é nestes termos que ele confessa ao doutor Cardoso: "não me sinto culpado de nada em especial, e ainda tenho desejado me arrepender, sinto nostalgia do arrependimento" (Antonio Tabucchi, Sostiene Pereira, cit., p. 121)
} 


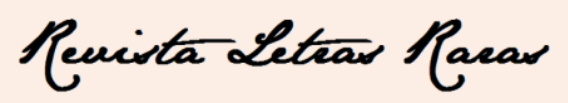

ISSN: 2317-2347 - Vol. 5, Ano 5, № 2 - 2016

Balzac: a partir dele, é "uma boa narrativa para se arrepender" e ele confessa que a novela é reconhecida. ${ }^{67}$ Estes personagens que se inclinam sobre seu passado são capazes de considerar quais foram os erros de suas vidas, pois eles se observam com o passar dos anos.

Mais que uma simples nostalgia do passado, há em Tabucchi, como em Pessoa, uma nostalgia do que poderia ter sido e que não foi. Essa "nostalgia do possível"68 é uma celebração do sonho e do desejo que partilham os narradores de Se está fazendo sempre tão tarde. Alguns se desviam e sobrepõem o que não foi às suas vidas presente. Na carta Livros nunca escritos, viagens nunca feitas, a obsessiva memória vai até a reinvenção do nãoacontecido: o protagonista relata os detalhes de uma viagem a Samarrcanda que ele e seu amor cúmplice não haviam feito. Ele chega à conclusão que as experiências imaginadas são mais preciosas que as realidades vividas. "Em suma, a verdadeira viagem não feita era Samarcanda. Não sei de uma lembrança inesquecível, e tão nítida, tão detalhada como possa dar só às coisas vividas de verdade na imaginação". ${ }^{69}$

Em português, nostalgia se diz saudade, e para Tabucchi, a saudade é também uma forma de melancolia. É um sentimento particular que leva o personagem a se deixar balançar pela estranha lembrança do que não tem lugar. Ela afeta o autor da Carta para escrever que, em sua carta hipotética, evoca para sua companhia os lamentos de um tempo que eles não viveram. "E te direi também que te espero, também se não se espera o que não se pode tornar, porque para tornar a ser o que fui,é preciso ser o que era, e isso é impossível.”70

O narrador espera alguma coisa que, não tendo tomado forma na realidade, não pode vir. Por definição, a saudade é uma nostalgia sem objeto que filtra nossa percepção do mundo. É igualmente a consciência de ser fixado ao tempo e dedicado a ele, como tudo o que nos cerca, até a morte. Em se tratando de especificar o senso dessa noção tipicamente lusitana, podemos citar uma breve passagem de uma entrevista que Tabucchi deu a Romana Petri.

[...] é uma palavra muito complexa que indica um ímpeto, um remorso, uma aspiração. A saudade pode ser nostalgia do futuro, um desejo do futuro, e também

\footnotetext{
${ }^{67}$ Ibideim, p. 120.

${ }^{68}$ Tal é o título definitivo de um dos ensaios que Tabucchi consagrou à obra de Pessoa (A nostalgia do possível. Sobre Pessoa) e que resume a obra intitulada A nostalgia, o automóvel, e o infinito.Leitores de Pessoa publicado pela primeira vez em 1998 nas edições Seuil.

${ }^{69}$ Antonio Tabucchi, Si sta facendo sempre più tardi, cit., p. 140.

${ }^{70}$ Ibidem, p. 209.
} 


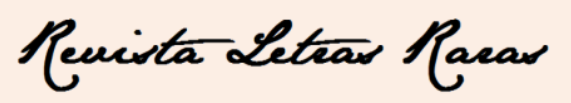

ISSN: 2317-2347 - Vol. 5, Ano 5, № 2 - 2016

uma nostalgia pelas coisas que teria podido ser e que não foram. É um pouco como o desejo de arrependimento de Pereira. ${ }^{71}$

Lembremos que, simbolicamente, Pereira mora em Lisboa na Rua da Saudade, e que no fim do capítulo 20 do romance, ele ilustra a nostalgia indefinível ("de uma vida passada e de uma vida futura ${ }^{72}$ ") que caracteriza este personagem da ficção.

\section{Contra a passagem do tempo}

Diante da fugacidade da existência humana, somente a escrita permite ao homem escapar de sua finitude e triunfar sobre o tempo. No caso de Tristano, o texto da história de sua vida (com seus altos e baixos, seus acasos e suas dores) é a garantia da perenidade de seu destino. Ele precisa de um escritor profissional que coloque em ordem suas lembranças dispersas para se dar a ilusão de que o tempo pode parar. Tristano crê na permanência da escrita (“em breve minha voz não estará mais lá, restará tua escrita” diz ele a seu interlocutor nas últimas páginas do livro ${ }^{73}$ ), e quer oferecer a seus contemporâneos e à posterioridade uma imagem de si mesmo que perdure. O subtítulo do romance, "uma vida", exprime a capacidade da escrita de imortalizar pelas palavras o curso da existência.

Mas Tabucchi é consciente de que a escrita biográfica pode deformar a realidade. Também o faz dizer por Tristano que "vocês, escritores, vocês são uns falsários ${ }^{74}$ ". O papel da biografia implica trapacear com as palavras ${ }^{75}$. O fato é que, apesar das reticências, os heróis se remetem ao escritor vindo a sua cabeceira porque a escrita é a única capaz de responder à sua busca pela eternidade.

\footnotetext{
${ }^{71}$ Romana Petri, “Uno scrittore pieno di gente” in Leggere no 61, giugno 1994, p. 72.

72 Antonio Tabucchi, Sostiene Pereira, Ed., cit., p. 159.

${ }^{73}$ Antonio Tabucchi, Tristano morre, Ed., cit., p. 156.

${ }^{74}$ Ibidem, p. 11

${ }^{75} \mathrm{O}$ tema da escrita falsa se encontra na coleção As aves do beato Angelico, onde podemos ler, em uma carta assinada por Antonio Tabucchi que, "os escritores são geralmente pessoas pouco confiáveis ainda mais quando tentam sustentar a prática do mais rigoroso realismo" (Antonio Tabucchi, As aves do beato Angélico, Palermo, Sellerio, 2005 [ $1^{a}$ edição: 1987], p. 47). Sobre as relações entre memória, verdade e escrita na obra narrativa de Tabucchi, aconselhamos a leitura do artigo já citado de Denis Ferraris (in Italies, nº11, cit., pp. 105-115).
}

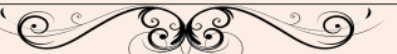




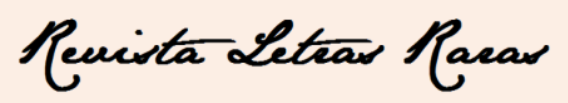

ISSN: 2317-2347 - Vol. 5, Ano 5, № 2 - 2016

A literatura é não só uma "forma de conhecimento"76", mas também "uma forma de memória ${ }^{77}$ ", segundo os próprios termos de Tabucchi. Também seus romances são saturados de referências a outros artistas de todas as épocas, em um jogo de intertextualidade pelo qual ele faz do seu o que os outros autores escreveram ou pensaram. O retorno sobre o passado cultural em sentido amplo concerne a três romances em particular. Em Requiem, o convidado com quem o narrador almoça no primeiro capítulo não é, senão, Fernando Pessoa. A conversação que engata entre os dois convívios o designa como iniciador do pós-modernismo. Afirma Pereira é um romance onde aparece como uma espécie de marca d'água uma história da literatura, com as alusões a Garcia Lorca, Pessoa, Camões, Maiakovski, Pirandello, Marinetti, D’Annnuzio, Balzac, Maupassant, Daudet, Bernanos e Mauriac. Quanto a Cabeça Perdida de Damasceno Monteiro, encontramos referências também dos escritores Flaubert, Jouhandeau, Gide, Camus, Hölderlin, Kafka bem como os filósofos Lukács e Carnap, e ao jurista Hans Kelsen. Como escreve Manuela Bertone, na base dessas citações há "uma necessidade ética de salvar ao menos alguns restos e de disseminar os pontos de conexão, lugares de memória textual através do qual tem lugar o reconhecimento da parte ativa que o passado literário exerce na constituição do presente da narrativa."78

As construções ficcionais de Tabucchi se apresentam como uma viagem em uma memória cultural e histórica. Em 1994, em uma entrevista concedida a Philippe Savary e Thierry Guichard ${ }^{79}$, o autor reconhece que a História é um tema cada vez mais importante em sua obra.

É um tema que me assombra, me obseca. A História do século vinte é bastante dramática e merece a atenção da literatura; é o século das grandes utopias políticas, das grandes esperanças, é também o século dos massacres, das perversões (Holocausto, totalitarismo, etc.).

Essa veia histórica não data dos anos 1980. Já em Praça da Italia, os personagens estão inseridos em uma duração coletiva, a da história. A família protagonista vê se desenrolar

\footnotetext{
${ }^{76}$ Antonio Tabucchi, "Elogio da literatura", in Italies, $n^{\circ}$ 11, cit., p. 21.

${ }^{77}$ Antonio Tabucchi, Ateliê do Escritor, Ed., cit., p. 136: "De fato, creio que a literatura seja uma forma de memória. A literatura é um meio, laico se quisermos, de responder às necessidades religiosas do homem". Essa concepção da literatura já se figurava sobre a contracapa de Praça da Italia, onde Tabucchi escreveu: "tenho sempre acreditado na literatura como memória."

${ }^{78}$ Manuela Bertone, "Frammenti per Requiem, allucinazione portoghese di Antonio Tabucchi" in Narrativa, C.R.I.X., Université Paris X-Nanterre, 1995, nº, p. 145.

${ }^{79}$ Esta entrevista foi publicada no número 7 de abril/junho de 1994 em Matricule des Anges.
}

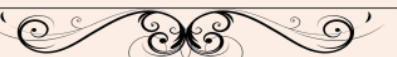




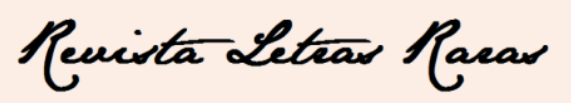

ISSN: 2317-2347 - Vol. 5, Ano 5, № 2 - 2016

a história de um século, da Unidade aos primeiros anos da República, com a ocupação de Roma em 1870, as guerras coloniais, o fascismo, a invasão da Etiópia, as duas guerras mundiais, as diferenças governamentais de Gasperi, a agitação social dos anos cinquenta. Em O pequeno navio, a reconstrução do passado de Capitano Sesto mistura história familiar e história da Itália, desde a proclamação do reino da Itália em 1861 até as lutas sindicais de 1969, passando pelo assassinato de Humberto $1^{\circ}$, os primeiros automóveis, a eletricidade, a guerra da Líbia, a Primeira Guerra mundial, o fascismo, a resistência, a deportação, a ascensão do comunismo, a morte de Togliatti.

Afirma Pereira é também um romance de inspiração histórica. A ação se situa em Lisboa, sob a ditadura de Salazar, precisamente em 1938, um ano crucial para a Europa na véspera da Segunda Guerra mundial. Nesta data, a guerra civil destruiu a Espanha, o nazismo triunfa na Alemanha e a Itália vive o fascismo. A atualidade é apresentada ao longo de todo romance, nos diálogos entre Pereira e os outros personagens (Monteiro Rossi, o servente Manuel, o doutor Cardoso, o amigo Silva, o diretor do jornal Lisboa ou o padre Antônio). É assim que o protagonista apresenta a Silva a situação crítica da Europa em 1938.

Mas tu lê os jornais e escuta o radio, sabe o que está se sucedendo na Alemanha e na Itália, são fanáticos, querem colocar o mundo a ferro e fogo [...] e tu sabes o que se sucede na Espanha, é uma carnificina, e ainda era um governo constitucional, tudo por culpa de um general intolerante ${ }^{80}$

O subtítulo do livro, "um testemunho", coloca a ficção em relação estreita com a realidade histórica através do filtro da experiência individual de Pereira ${ }^{81}$, que acaba por tomar consciência da brutalidade cotidiana do regime em lugar da necessidade de se mobilizar contra a opressão salazarista. O romance é subtendido como um combate pela liberdade de expressão.

Enfim, em Tristano morre, o herói recompõe seu passado partindo de um episódio dramático da história do século XX, a ocupação da Grécia pelas tropas italianas e alemãs. O autor se beneficia para lembrar que é preciso lutar contra o esquecimento. Não se pode esquecer, por exemplo, as duzentas milhões de pessoas mortas no dia 6 de agosto de 1945 no

\footnotetext{
${ }^{80}$ Antonio Tabucchi, Sostiene Pereira, cit., p. 64.

${ }^{81}$ Sobre o valor do testemunho histórico e ideológico de Afirma Pereira, ver Flavia Brizio-Skov, op., cit., pp. 127-149.
} 


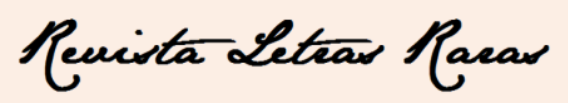

ISSN: 2317-2347 - Vol. 5, Ano 5, № 2 - 2016

bombardeamento atômico de Hiroshima ${ }^{82}$. A resistência à passagem do tempo passa pela escrita e o dever da memória entra nas funções do escritor, segundo Tabucchi. ${ }^{83}$

Escrever significa testemunhar o passado, mas também o presente, e a literatura deverá servir à verdade e à justiça. A cabeça perdida de Damasceno Monteiro coloca em causa as sociedades europeias do fim do século XX, a partir da situação portuguesa em 1996. O tema do romance - a descoberta do cadáver decapitado de Damasceno Monteiro em um parque nos subúrbios de Porto - se inspira de uma notícia concreta e real, o assassinato do jovem Carlos Rosa em um comissariado da Guarda Nacional Republicana de Sacavém, no subúrbio de Lisboa ${ }^{84}$. Para além da notícia, Tabucchi denuncia os abusos policiais, a injustiça, a exclusão das minorias étnicas. A tortura é um dos leitmotivs do livro. No capítulo 16, o advogado Mello Siqueira a apresenta como um flagelo a nível nacional e mundial: "Recapitulando: London foi torturado pelos comunistas, Alleg foi torturado porque era comunista. O que confirma que a tortura pode vir de qualquer parte, é esse o verdadeiro problema." ${ }^{, 85}$

No capítulo 20, na ocasião do processo contra o sargento Titanio Silva, ele retorna sobre o tema da tortura usada com os comissariados portugueses e relembra os serviços infligidos pela Gestapo aos juízes durante a Segunda Guerra mundial citando o exemplo de Jean Améry ${ }^{86}$. O romancista se questiona sobre o problema da responsabilidade dos indivíduos face à História e se levanta em testemunha dos que mostram o inverso do discurso do poder.

Antonio Tabucchi é um homo melancholicus como o narrador de Forbidden Games $^{87}$ ? Se sim, não podemos ver nesta obra a busca de uma escrita que exorciza suas obsessões que são a passagem do tempo, a morte ou o remorso? A vida, a morte e o tempo

\footnotetext{
${ }^{82}$ Antonio Tabucchi, Tristano morre, cit., p. 107: "esta manhã a primeira bomba atômica utilizada como arma de destruição em massa cai sobre a cidade do nosso mundo aniquilando e incendiando duzentas mil pessoas"

${ }^{83}$ Sobre os deveres do escritor segundo Tabucchi, leiamos o artigo de Yannick Gouchan, "A figura do escritor na obra de Antônio Tabucchi” in Italies, $\mathrm{n}^{\circ}$ 11, cit., pp. 191-213.

${ }^{84} \mathrm{Na}$ nota colocada no fim do livro, Tabucchi especifica que Carlos Rosa foi torturado e morto na noite de 7 a 8 de maio de 1996 e que seu corpo, sem cabeça, foi encontrado em um parque público.

${ }^{85}$ Antonio Tabucchi, La testa Perduta di Damasceno Monteiro, cit., p. 176.

${ }^{86}$ Ibidem, p. 221.

${ }^{87}$ Antonio Tabucchi, Si sta facendo sempre più tardi, cit.,p. 41: "o médico me disse: este é um caso clássico de homo melancholicus". A questão pode especialmente ser colocada, já que Tabucchi declarou no Ateliê do Escritor que "naturalmente, toda literatura é um pouco autobiográfica." (cit., p. 53)
} 


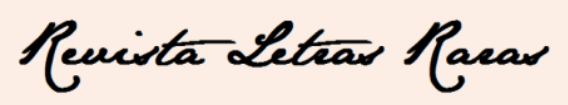

ISSN: 2317-2347 - Vol. 5, Ano 5, № 2 - 2016

são os temas nos quais, diante de toda eternidade, os escritores sempre foram confrontados. No caso de Tabucchi, à questão sobre o senso da vida e das coisas, se reúnem também a relativização do conceito de tempo que perde sua univocidade. Ele reflete a ambiguidade do mundo no qual vivemos.

A literatura deve "provocar uma certa intranquilidade" segundo o convidado de Requiem $^{88}$. Tal é o efeito que produzem os romances de Tabucchi sobre o leitor, escritor do equívoco e do estranhamento da existência, que introduz o insólito nas suas ficções, que povoa com personagens nostálgicos que nos toca com suas dúvidas. Ele adora sondar a alma na penumbra interior do homem, nas angústias das quais ele dá uma dimensão universal.

\section{Marie-Line CASSAGNE}

CASSAGNE, Marie-Line. Le temps dans les romans d'Antonio Tabucchi: Analyse de la matière et du discours narratif. Crhoniques Italiennes, vol 13, 2008. Disponível em <http://chroniquesitaliennes.univ-paris3.fr/PDF/web13/Cassagne13.pdf $>$ Acesso em 22 de maio de 2015.

Recebido em: 30/08/2016

Aceito em: 20/09/2016

\footnotetext{
${ }^{88}$ Antonio Tabucchi, Requiem, cit., p. 119. "Pois é, confirmou ele, comigo é sempre assim, mas olhe, não acha que é isso mesmo que a literatura deve fazer, desassossegar?"
} 